Erratum

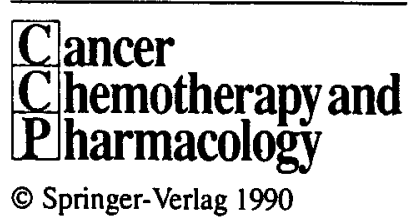

\title{
Identification of anthracyclines and related agents that retain preferential activity over Adriamycin in multidrug-resistant cell lines, and further resistance modification by verapamil and cyclosporin $A$
}

Helen M. Coley, Peter R. Twentyman, and Paul Workman

MRC Clinical Oncology and Radiotherapeutics Unit, Hills Road, Cambridge CB2, 2QH, U. K.

In: Cancer Chemother Pharmacol 24: 284-290

On p. 285 of the above contribution an extended version of the figure showing the compound structures should replace Fig. 1. The authors' new preferred version is given below.

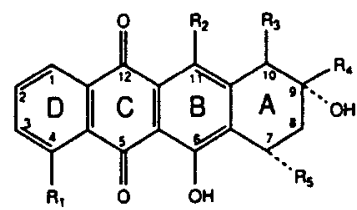

$\begin{array}{cccc} & \text { Adriamycin } & \text { 4'-Epi-adriamycin } & \text { 4'-Deoxy-adriamycin } \\ \mathrm{R}_{1} & \mathrm{OCH}_{3} & \mathrm{OCH} \mathrm{H}_{3} & \mathrm{OCH}_{3} \\ \mathrm{R}_{2} & \mathrm{OH} & \mathrm{OH} & \mathrm{OH} \\ \mathrm{R}_{3} & \mathrm{H} & \mathrm{H} & \mathrm{COCH} \\ \mathrm{R}_{4} & \mathrm{COCH} & \mathrm{COH} & \end{array}$

Morpholinyl-adriamycin

4'-Deoxy-
4'-iodo-adriamycin

4-Demethoxy-daunorubicin

$\begin{array}{ll}\mathrm{R}_{1} & \mathrm{OCH}_{3} \\ \mathrm{R}_{2} & \mathrm{OH} \\ \mathrm{R}_{3} & \mathrm{COC \textrm {H } _ { 2 } \mathrm { OH }} \\ \mathrm{R}_{4} & \end{array}$

$\mathrm{OCH}_{3}$

H

$\mathrm{OH}$

$\mathrm{OH}$

$\mathrm{H}$

H

$\mathrm{COCH}_{2} \mathrm{OH}$

$\mathrm{COCH}_{3}$
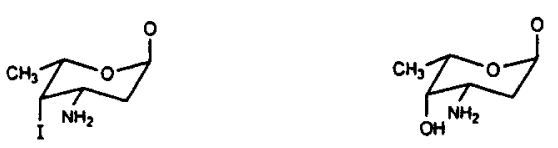

Fig. 1 continued 
388

Ro 31-1215

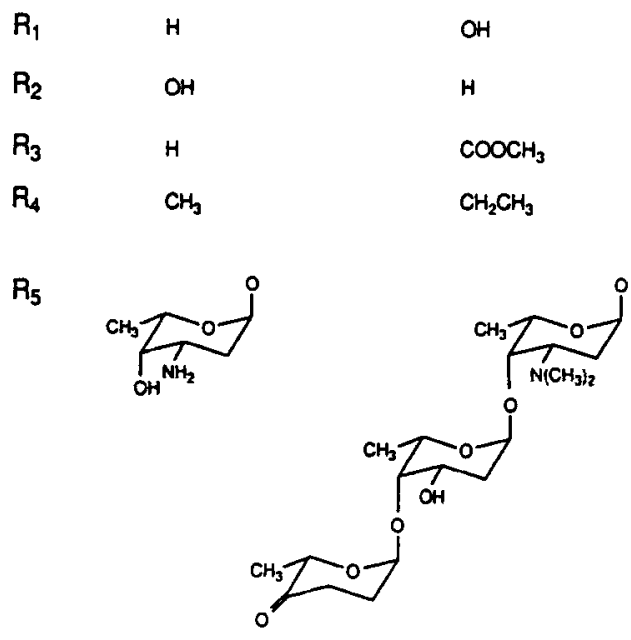

Aclacinomycin A

$\mathrm{OH}$
$\mathrm{OH}$

OH
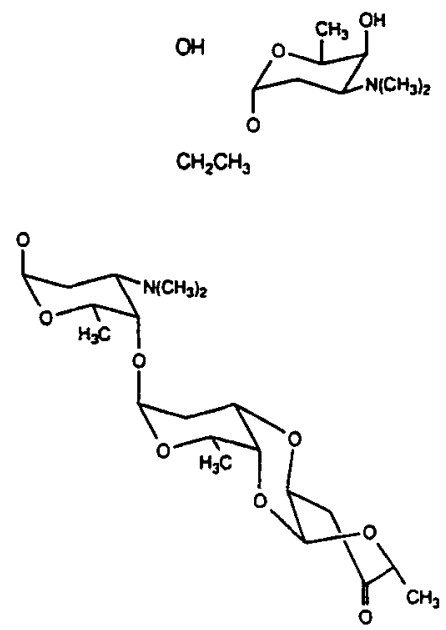

Mitoxantrone

Anthrapyrazole Cl941
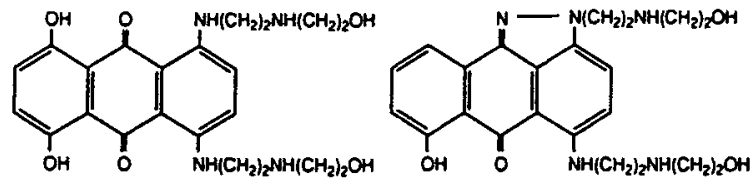